\title{
TOOTHPASTES AVAILABLE IN THE MALAYSIAN MARKET
}

S Musa, R Saub. Toothpastes available in the Malaysian market, Annals Dent Univ Malaya 1998; 5: 45-48

\begin{abstract}
This study was undertaken to investigate the number and types (fluoride or non-fluoride) of toothpaste products available in the Malaysian market based on the label. Thirty-five brands of toothpaste were identified, of which ten (29\%) were specifically recommended for children. Two of the children's toothpaste recommended that children below seven years old use a pea size amount of toothpaste. One (3\%) was recommended for both children and adult. The remaining 24 (69\%) did not state if they were recommended for either children or adults. To improve the flavour of the toothpastes, a variety of flavours had been added especially in children's toothpaste. Almost half of the toothpastes were for prevention of tooth decay and gum disease. Other indications were for tooth sensitivity, tooth whitening and stain removal. Twentyseven $(77 \%)$ of the toothpastes were imported, while eight $(23 \%)$ were made in Malaysia. Twenty-six $(74 \%)$ of the toothpaste contained fluoride and the most common type of fluoride used was sodium monofluorophosphate (NaMFP). The fluoride concentration was not labeled in more than half $(63 \%)$ of the fluoridated toothpaste. Of those that were fluoridated, different units of measurement were used. As there is no uniformity in the labelling of these products, it is recommended that the responsible authorities should take more action in enforcing proper labelling of the fluoride concentration in the toothpaste using standardized units.
\end{abstract}

Keywords: fluoride toothpaste, children, labelling

\section{INTRODUCTION}

The prevalence of dental caries especially among schoolchildren has declined worldwide (1). In Malaysia, the mean DMFT for 12-year-old children has decreased from 3.7 in 1971 to 2.4 in 1988 (2). Several factors have been thought to bring about this reduction and fluoride in drinking water and in toothpaste have been shown to contribute to this decline (3).

Numerous studies have shown that water fluoridation has a great impact on the reduction of dental caries prevalence (1). However, in areas where the water supply is not fluoridated, toothpaste has become a source of fluoride for caries prevention. The WHO in 1993 (3) reported that in industrialized countries, the decline in the prevalence of dental caries in the past 20 years was attributed mainly to the widespread use of fluoride toothpaste. Fluoridated toothpaste has been suggested to be responsible for 20-35 per cent of caries reduction in developed countries (4).

Although fluoride has been shown to be an effective agent in caries prevention, overdoses can lead to unwanted effect such as developmental defects of enamel and bones. Although fluoridation of water supplies in Malaysia is widespread, toothpastes are also easily accessible since 1970's $(2,5)$.

Several studies have been conducted to determine the

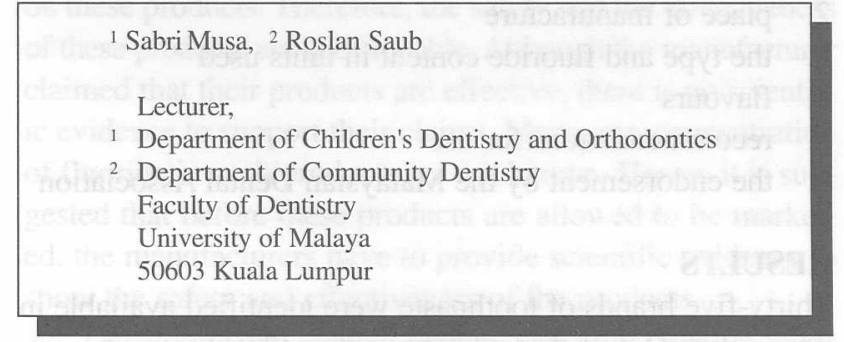

prevalence of the enamel defects. Razak and Hussein (6) in 1986 examined 11-12-year-old children from a fluoridated area in Selangor. They found that the prevalence of enamel defects was $72.5 \%$ and over $90 \%$ of the affected teeth have the diffuse patchy type, which has been related to a mild form of fluorosis. In 1986, a study by the Dental Division, Ministry of Health (7) in Johore, on 12-year-old children found that $81.2 \%$ of the children from the areas with fluoridated water supply had diffuse opacities, while only $56.0 \%$ of the children from areas with unfluoridated water supply exhibited diffuse opacities. In addition, the children who were involved in those studies grew up at the time when the fluoride toothpaste was widely used in Malaysia. Most studies had found that the prevalence of the developmental enamel defects was high, however, one study had found that generally its psychosocial impact on 16-year-old school children was low (16).

In Malaysia recently, the issue of fluoride in the toothpaste has received considerable public attention in discussion, claiming that fluoride is a poison. In fact, all chemical products are poisonous when consumed in large amounts. For all chemical products there is a recommended therapeutic dose and this also applies to the use of fluoride in fluoridated toothpaste.

The influx of toothpastes of all kinds and brands into the Malaysian market seems to be occurring without any control. With the increasing concern from the public on the fluoride issue, it seems necessary that precautionary actions are undertaken to ensure safe and continued use of fluoride toothpaste. In developed countries however, while realizing that the impact of fluoridated toothpaste has led to caries decline, action has been taken to prevent fluorosis i.e through labelling and messages containing advice on the box. However different standards have been used in Malaysia.

Therefore the purpose of this study was to investigate the number and types (fluoride or non-fluoride) of toothpaste products available in the Malaysian market based on the label.

\section{Materials and Method}

Five selected supermarkets and four selected pharmacies around Petaling Jaya, Selangor were visited. The selection of the supermarket and pharmacies was based on the location and popularity. The assumption made in this study was all types of toothpastes available in any part of Malaysia will be available in the study area. All types of toothpastes sold were identified. The following information written on the box/pack were recorded 
1. the brand name

2. place of manufacture

3. the type and fluoride content in units used

4. flavours

5. recommendations for use

6. the endorsement by the Malaysian Dental Association

\section{RESULTS}

Thirty-five brands of toothpaste were identified available in the market. Out of these, twenty-seven (77\%) were imported. This included two herbal toothpastes, and only eight $(23 \%)$ were made locally (Table 1$)$. Among the imported toothpastes, four were from USA; three from UK, Canada, Japan and Indonesia; two from Australia, Singapore and France; one from India, Hong Kong, Korea, Italy and China (Table 2 and 3).

Fourteen $(40 \%)$ of the toothpastes were recommended for prevention of tooth decay and gum diseases. Other uses were for sensitive teeth (15\%), as teeth whitening agents $(5 \%)$ and stain removal $(9 \%)$. Nine $(26 \%)$ of the toothpastes did not state any special usage indications.

Ten $(29 \%)$ of the toothpastes were specifically recom-

Table 2: Fluoridated toothpastes in the Malaysian market

\begin{tabular}{|c|c|c|c|c|}
\hline & Brand name & Manufacturer & Type of Fluoride & {$[\mathrm{Fl}]$} \\
\hline 1 & Colgate & Malaysia & $\mathrm{MFP}$ and $\mathrm{NaF}$ & Not given \\
\hline 2 & Colgate Total & Malaysia & $\mathrm{NaF}$ & Not given \\
\hline 3 & Fresh end white & Malaysia & 2 Fl system & Not given \\
\hline 4 & SparkelIndonesia & NaMFP & Not & given \\
\hline 5 & Darlie & Hong Kong & NaMFP & Not given \\
\hline 6 & Sensodyne-F & Australia & NaMFP & $7.6 \mathrm{mg} / \mathrm{g}$ \\
\hline 7 & Oral-B & Canada & Stannous FL & $4.0 \mathrm{mg} / \mathrm{g}$ \\
\hline 8 & Oral-B & Canada & $\begin{array}{l}\text { Hydroxyapatite } \\
\mathrm{NaF}\end{array}$ & $17.0 \%$ \\
\hline 9 & Oral-B & Canada & $\mathrm{NaF}$ & $0.02 \% \mathrm{w} / \mathrm{w}$ \\
\hline 10 & Kodomo Lion & Japan & Not given & Not given \\
\hline 11 & Zact & Japan & NaMFP & Not given \\
\hline 12 & Tooty & Malaysia & NaMFP & Not given \\
\hline 13 & Zwitsal & Indonesia & NaMFP & $0.1 \%$ \\
\hline 14 & Uncle Doc & USA & NaMFP & Not given \\
\hline 15 & Rembrandt & USA & NaMFP & $0.76 \%$ \\
\hline 16 & Clinomyn & UK & NaMFP & $0.76 \%$ \\
\hline 17 & Clinomyn & Singapore & NaMFP & Not given \\
\hline 18 & Topol Plus & USA & NaMFP & Not given \\
\hline 19 & Mentadent P & UK & NaMFP & $0.8 \%$ \\
\hline \multirow[t]{2}{*}{20} & Fluocaril Bi-fluore & France & NaMFP & $0.683 \%$ \\
\hline & & & $\mathrm{NaF}$ & $0.022 \%$ \\
\hline 21 & Zoothpaste & Korea & NaMFP & Not given \\
\hline 22 & Boots & UK & $\mathrm{NaF}$ & $0.025 \%$ \\
\hline 23 & 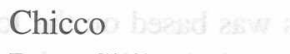 & Italy & NaMFP & Not given \\
\hline 24 & Daun Sirih & Indonesia & Fl mineral & Not given \\
\hline 25 & Polleney & China & Not given & Not given \\
\hline 26 & Dent Fresh & Malaysia & NaMFP & Not given \\
\hline
\end{tabular}

[FL] denote fluoride concentration
Table 1: Number and percentage of local and imported toothpastes in Malaysian market

\begin{tabular}{lrrrrrr}
\hline \multirow{2}{*}{ Type of toothpaste } & \multicolumn{4}{c}{ Manufacturer } \\
\cline { 2 - 8 } & \multicolumn{1}{c}{ Imported } & \multicolumn{2}{c}{ Local } & \multicolumn{2}{c}{ Total } \\
& $\mathrm{n}$ & $\%$ & $\mathrm{n}$ & $\%$ & $\mathrm{n}$ & $\%$ \\
\hline Fluoridated & 21 & 77.8 & 5 & 62.5 & 26 & 74.3 \\
Nonfluoridated & 6 & 22.2 & 3 & 37.5 & 9 & 25.7 \\
Total & $\mathbf{2 7}$ & $\mathbf{7 7 . 1}$ & $\mathbf{8}$ & $\mathbf{2 2 . 9}$ & $\mathbf{3 5}$ & $\mathbf{1 0 0 . 0}$ \\
\hline
\end{tabular}

mended for children. One was recommended for both children and adult while the remaining twenty-four (69\%) did not state whether they were recommended for either children or adult or both. Two brand of the children's toothpastes had a message "children below seven years old use only a pea size amount of toothpaste" written on the box.

Twenty-six (74.3\%) of the toothpastes contained fluoride (Table 1). The most common type of fluoride used was sodium monofluorophosphate (59\%). Other fluoride compounds used in the toothpaste were sodium fluoride (19\%), stannous fluoride $(15 \%)$, hydroxyapatite sodium fluoride (4\%), fluoride mineral (4\%) and '2 fluoride system' (4\%). However, 16 of the 26 fluoridated toothpastes did not indicate the fluoride concentration. For those which indicated the fluoride content, different units of labelling the concentration were used such as $\mathrm{mg} / \mathrm{g}, \% \mathrm{w} / \mathrm{w}$ and $\%$.

The concentration of fluoride in the toothpastes was clearly labelled for 11 out of 26 toothpastes which contained fluoride. These were Sensodyne-F (7.6mg/g), OralB (for tooth and gum care, $4 \mathrm{mg} / \mathrm{g}$; for sensitive teeth, $17 \%)$, Rembrandt $(0.76 \%)$, Clinomyn $(0.76 \%)$, Mentadent-P $(0.8 \%)$ and Fluocaril bifluore $(0.683 \%, 0.0221 \%)$. For the children's toothpaste the concentration of fluoride were stated by Oral-B $(0.02 \%$ w/w) Z Zwitsal $(0.1 \%)$ and Boots $(0.025 \%)$.

Table 3: Non fluoridated toothpastes in Malaysian market

Brand name Manufacturer

\begin{tabular}{lll}
\hline 1 & Sensodyne & Australia \\
2 & Zact & Japan \\
3 & Dabur & India \\
4 & Uncle Doc & USA \\
5 & Pyodontyl & France \\
6 & Tollyjoy & Singapore \\
7 & Zaitun (adult) & Malaysia \\
8 & Zaitun (children) & Malaysia \\
9 & Promisce & Malaysia \\
\hline
\end{tabular}


Eight out of 9 children's toothpastes contained different fruit flavours such as banana, strawberry, melon, grape, orange, apple, mixed fruit, tropical fruit and chewing gum flavour.

Only three toothpastes had the endorsement from the Malaysian Dental Association. These were Colgate, Colgate Total and Sparkle.

\section{DISCUSSION}

In Malaysia, there are many varieties of toothpastes sold in the market. However, most of the brands are imported. The fluoride concentration in the imported toothpastes may not be very suitable for the Malaysian use. Thus the responsible body should analyse and ensure that the fluoride concentration in the toothpastes is suitable and safe before they are allowed to be marketed in this country.

Out of 35 brands available, only three brands were given the endorsement by the Malaysian Dental Association (MDA), two were locally manufactured (Colgate and Colgate Total) and one was imported (Sparkle). Although they have been endorsed, these products were not uniformly labelled. Furthermore, these brands do not indicate the use for either children or adults. Studies have shown that children tend to swallow the toothpaste while brushing and it has become one of the sources of fluoride intake (10-14). The amount of fluoride intake during the first 6 years is critical in children because it can cause enamel opacities in the permanent dentition $(8,9,13,14)$. This is important because the fluoride concentration which are recommended for use by children are different from that of an adult. From the results of several scientific studies and evidence at present, children under the age of 6 years who were found to be at low risk of developing dental caries are recommended to use a toothpaste containing no more than 600 parts per million (ppm) of fluoride (15). Those with a higher risk of developing caries should use the toothpaste containing $1000 \mathrm{ppm}$ of fluoride (15).

Most of the toothpastes sold in Malaysia indicated the type of fluoride content such as monofluorophosphate, sodium fluoride, and sodium monofluorophosphate. However, the concentration of the fluoride was not stated. Several western countries have made labelling of fluoride concentration and composition mandatory. However, this study found that different manufacturers used different units in labelling. Therefore, to avoid confusion to the customers and even to the dentists, standardised unit such as in ppm should be used $(14,15)$.

This study also identified several toothpastes labelled as "family packs" being sold in the market. These toothpastes were meant for use by the whole family including children. Although it is much cheaper, the toothpaste may not be suitable for use by children due to the different concentrations of fluoride which is recommended for children and adults. Therefore, any toothpaste sold in the market should clearly state whether it is indicated for use by children or adults.

Herbal toothpastes were also available in the market. Two brands were identified, both were imported, one was from India (Dabur) and the other from Indonesia (Daun
Sirih). However, no known clinical study has been carried out on these products. Therefore, the safety and the effectiveness of these products are questionable. Although the manufacturer claimed that their products are effective, there is no scientific evidence to support their claims. Moreover, concentration of fluoride in such products are not known. Hence, it is suggested that before these products are allowed to be marketed, the manufacturers have to provide scientific evidence to show the safety and effectiveness of the products.

Developmental enamel defects will only develop when excessive amount of fluoride is ingested during the formation of teeth. If excessive fluoride intake occurs during the first six years of life, all permanent teeth will be at risk, whilst if this occurs during the first three years of life, only permanent incisors will be at risk $(8,9)$. Therefore, parents are advised to supervise and train their children to use only a small peasized amount of toothpaste. A simple message of advice for parents on the label is highly recommended.

\section{CONCLUSION}

There are many types of toothpastes which are available in the Malaysian market. They are sold either for cosmetic or therapeutic purposes. To enable a potential consumer to make his/her selection easily and safely, proper labelling is recommended. Authorities such as the Ministry of Health and the Malaysian Dental Association should play their role in monitoring and ensuring that these products are safe for people to use.

\section{ACKNOWLEDGEMENTS}

We would like to thank Associate Prof. Dr Nik Noriah Nik Hussein for her comments and advice.

\section{REFERENCES}

1. Murray JJ, Naylor MN. Fluorides and dental caries. In: Murray JJ, Prevention of Oral Diseases. 3rd. ed., Oxford University Press, 1993: 32-67.

2. Reports of Dental Epidemiology Surveys in Malaysia, Dental Services Division, Ministry of Health Malaysia, 1991.

3. WHO. Fluorides and Oral Health. Report of a WHO Expert Committee on Oral Health Status and Fluoride Use, Geneva, 1993.

4. Rahimah Kadir. What's in a toothpaste. New Straits Time, 22 February 1998.

5. Majid Z. Hussein NN, Bagramian RA. The prevalence of caries and developmental enamel defects in an adult population in Malaysia. Dent J Malaysia 1995; 16 (1): 33-39.

6. Razak IA, Hussein NN. A study of enamel defects in 12 years old subjects in a fluoridated area. Dent J Malaysia 1986; 9: 21-26.

7. Dental Division, Johore, Malaysia. Epidemiological Survey of developmental defects of dental enamel in Johore 1986. Johore Bahru: Government Printers 1986.

8. Evans RW, Stamm JW. An epidemiologic estimate of the critical period during which Human maxillary central incisors are most susceptible to fluorosis. J Public Health 
Dent 1991; 51 (4): 251-9.

9. Evans RW. Refining the estimate of the critical period for susceptibility to enamel fluorosis in human maxillary central incisors. J Public Health Dent 1995; 55 (4): 23849.

10. Pendrys DG. Risk of fluorosis in a fluoridated population. Implications for the dentist and hygenist. J Am Dent Assoc 1995 ;126: 1617-24.

11. Osuji OO, Leake JL, Chipman ML, Nikiforuk G. Locker D, Levine N. Risk factors for dental fluorosis in a fluoridated community. J Dent Res 1988; 67: 1488-92.

12. Milsom K, Mitropoulos CM. Enamel defects in 8-yearold children in fluoridated and non-fluoridated parts of Cheshire. Caries Research 1990; 24: 286-9.
13. Rock WP. Young children and fluoride toothpaste. Br Dent J 1994; 177: 17-20.

14. Holt RD, Murray JJ. Developments in fluoride toothpastes - an overview. Comm Dent Health 1997; 14: 4-10.

15. Holt RD, Nunn JH, Rock WP, Page J. British Society of Paediatric Dentistry: A Policy Document on Fluoride Dietary Supplements and Fluoride Toothpastes for Children. Int J of Paed Dent 1996; 6: 139-142.

16. Sujak SL, Mohd-Dom TN, Abdul-Kadir R. Prevalence and psychosocial impact of developmental defects in a sample of Malaysian adolescents. In Proceedings, 12th IADR Congress of South East Asian Division, Phuket, Thailand. 1997 pg 95. 